\title{
Calendario Cultural de Italia en 1946
}

La producción intelectual de Italia, durante el año 1946, ha estado desgraciadamente influída por el hecho, exclusivamente político, del es tablecimiento de la República.

La mayoría de los escritores italianos eran y son republicanos, -en una proporción mayor que el 53 por ciento de electores que votó por la República, - pero la acritud de la polêmica, —en la que se invirtieron 3 mil millones de liras, - frustró o afeó su obra netamente intelectual.

Al contrario, la derrota militar/con su feo cortejo de recriminaciones y miserias, (1) y el severo enjuiciamiento de los escritores fascistas o colaboracionistas han paradójicamente incrementado la producción intelectual ya que las principales obras que se han publicado se refieren a la Tiranía como "Cristo si è fermato a Eboli" de Carlos Levi o al admirable heroismo de la Resistencia como "Paura al Alba" de Arrigo Benedetti, "Uomini e no" de Elio Vittorini y "Villagi bruciano" de Persio Nesti.

Una vez más se ha cumplido asi la ley de que las ideas sólo germinan y florecen en un clima de libertad.

Los principales hechos que acaecieron en Italia, en el Campo de la Cultura, durante el año pasado, son los siguientes:

En Milán, en el mes de mayo, se realizó el Congreso "de las Letras y Artes". Antes Angiolletti había instado a los intelectuales italianos a discutir públicamente el problema de la crítica. En esa ocasión y después en el Congreso de Milán, previa una sustanciosa ponencia de Sergio Solmi, se arribó a la conclusión de que "el concepto croceano de la autonomía del Arte no ha sido superado todavía".

Sin embargo el mismo Solmi afirmó que "la crítica debe versar sobre el contenido moral de la obra" y que debe evitar, tanto el peligro de la deshumanización del arte como el de que ella se convierta en instrumento de las pasiones políticas.

(1) En Italia ha cundido, como en ningún otro país, esa suerte de canibahismo que es ol Mercado o Bolsa Negra. 
En el último número de "Mercurio" (nov. dic. 1946) se lamenta Godofredo Bellonci de que "sólo la literatura de espíritu y forma extranjeras han cundido este año".

Parece referirse, principalmente, al cúmulo de traducciones que se han editado las principales de las cuales son: El Teatro Contemporáneo Ruso (Editorial O. E. T.); Puskin, La Comedia Humana de Balzac, Poe, Whitman, Faulkner y Hemingway (Editorial di Carlo).

Se han editado también dos traducciones de orden superior: la in superable versión de "La Odisea" de Salvatore Quasimodo y los 40 sonetos de Shakespeare realizada, magistralmente, por G. Ungeretti.

Pero, además, se han publicado obras de cautivante originalidad y dos de ellas "capitales" como la de Benedetto Croce, "Poetas y Escritores del Renacimiento", y la de Giovanni Papini, "Cartas a los hombres del Papa Celestino Sexto".

Apenas apareció este magnífico libro, en el que un Papa imaginario pero cuyo nombre tiene curiosas reminiscencias históricas aparece denunciando las mil formas de Materialismo que en estos momentos tienden a sofocar el espíritu humano y frustrar su elevado destino, traduje el último de sus capítulos y lo envié a Lima, para que fuera conocido, habiéndose publicado en la edición dominical de "El Callao" correspondiente al 10 de noviembre del año pasado.

La producción "menor" ha sido estimulada y resarcida por los Premios Literarios, que ho ise/discerníam desde antes de la guerra.

El premio milanes promovido por "El Corriere Lombardo" se dividió, -honor y dinero, entre Alberto Moravia, comunista, por su obra "Agustín"; Carlos Levi por su magnífico romance, ya nombrado "Cristo si è fermato a Eboli" y Gianna Manzini por sus "Cartas al Editor"; el premio "Viareggio" entre Umberto Saba, poeta triestino y cantor de la italianidad de Trieste, y el ignorado e ignorante M. Micheli por su novela "Pan Duro" y el premio genovés entre Isidoro Montanelli autor de la novela "Aquí no reposamos" y Corrado de Vita por su "Yo estoy vivo" obras consideradas generosamente como prenarrativas o folletinescas.

El más importante de los premios literarios, el Premio Vendemmia, se otorgó al escritor siciliano Vitaliano Brancati, autor de "Don Juan en Sicilia" por sus nuevos relatos titulados "El Viejo con Botas", hondamente dramáticos, breves, pulidos, plenos de sugestiones de elevada trascendencia moral.

El acontecimiento intelectual más importante del año 1946 ha sido, en Italia, el Congreso de Filosofía realizado en Roma del 15 al 20 de noviembre. 
Fué promovido por el Instituto de Estudios Filosóficos y auspiciado y presidido por Guido Gonella, el Ministro democristiano de Instrucción Pública.

La presidencia y dirección efectivas las ejerció con notable autoridad el Prof. Giovanni Caló, de la Universidad de Florencia.

Concurrieron representantes de 15 naciones, incluso del Perú, qus estuvo dignamente representado por Alberto Wagner de R.

Las ponencias versaron sobre estos 3 temas:

1. El materialismo histórico.

2. El existencialismo.

3. El principio de la Ciencia y análisis del lenguaje.

El primer tema fué discutido apasionadamente.

El Prof. A. Baffi afirmó, que "el materialismo histórico forma un nuevo humanismo, ni mítico ni utópico, sino histórico y progresivo, median. te el cual puede restablecerse la unidad humana.

Julien Benda fué todavía más concluyente: "el marxismo, dijo, quie. re construir una sociedad en la que el obrero viva emancipado y se consume la reivindicación total de los derechos del hombre".

Prevalecieron, sin embargo, las opiniones adversas.

"El materialismo histórico no es ni puede ser una ético filosófica", sos. tuvo el Prof. Petruzzellis.

"Es lo mismo materialismo filosófico que comunismo político", afirmó el Prof. Ugo Spirito.iblioteca de Letras

"El marxismo es sólo un economicismo abstracto" (Prof. Calò), "es inconciliable con la libertad" (Prof. Drago), "tiende a suprimir al individuo y a entronizar el totalitarismo" (Prof. Mario Gori) y para el Prof. Fessard "tiene el mismo origen que el nazismo: la famosa dialéctica del Patrón y del Esclavo de la Fenomenología de Hegel".

El Prof. Rafael Calvo resumió las ideas adversas al marxismo afirmando que "no es una teoría científica de la historia que justifique la marcha inevitable de la humanidad hacia una sociedad sin clases". "El determinismo, dijo, y la reducción de los factores históricos a los económicos, son afirmaciones dogmáticas y no crítico-científicas". "Histórica mente, concluyó, puede demostrarse la primacía de lo espiritual sobre lo económico tanto en la historia de la cultura como en la de la Economía".

Igualmente apasionadas fueron las discusiones referentes al existen. cialismo.

Los motivos eternamente humanos que él contiene, —angustia, noia o tedio de vivir, esa grave "náusea" por emplear la imagen brutal de 
Sartre, $\tan$ hondarnente sentidas hoy como en las épocas de San Agus tín y de Pascal,- fueron cálida y armoniosamente expuestos por los distintos delegados.

Enrique Castelli, G. Caloggero, Antonio Alliotta y Nicola Abbagnano representaron brillantemente el existencialismo italiano y Benda, Boyer, Berger, Forest, Marcel y Poliard la inspirada y homogénea corriente francesa.

Eugenio d'Ors y Gonzales Alvarez representaron cabalmente el ma. cizo idealismo español.

Boyer fué quien, con más orden y detenimiento, estudió los dos elementos del existencialismo: el sentimiento de la irreducibilidad de la existencia y esa inquietud que sólc se calma y se colma en la existen. cia trascendente, necesaria, absoluta, de un ser en sí, sin principio y sin fin, todo actividad $\mathrm{y}$ "objeto final de toda existencia contingente".

Este elemento, sutilmente religioso, fué resumido por el Prof. A. Schwientek en esta fórmula feliz: "senza trascendenza non c'e existenza" "sin trascendencia no hay existencia" que expresa la nueva corriente del existencialismo que ha superado el pesimismo ateo de Heidegger, de Camus y de Sartre para crear un optimismo que no es necesariamente cristiano o católico pero que es de todas maneras profundamente religioso.

Por eso Su Santidad el Papa Pío XII al recibir a la mayoría de los filósofos del Congréso presidida póre Jācques Maritain, pudo decirles: "¿qué otro camino que la desesperación queda a la Filosofía si no busca y encuentra sus soluciones finales en Dios, en la inmortalidad personal Y en la eternidad?" (1).

Sé que en el desarrollo del tercer tema, -el principio de la ciencia y el análisis del lenquaje,- se llegaron a conclusiones decisivas pero como no pude asistir a las sesiones y la Secretaría del Congreso no ha publicado todavía el resumen de las ponencias, no puedo referirme particularmente a ellas. Lo haré cuando sean publicadas.

Aparte del valor de las conclusiones estrictamente técnicas o filosóficas, el Congreso de Filosofía de Roma fué un acto admirable de valor y de tolerancia.

De tolerancia no sólo porque las opiniones más radicalmente desacordes se expresaron con absoluta libertad y se escucharon con el más

(1) Alberto Wagner de Reyna sostuvo que no debe dividirse el existencialismo en ateo y cristiano ya que él es, por su propia naturaleza, neutral en materia religiosa.

Fué escuchado con mucha atención y respeto. 
hondo y sincero respeto sino también porque ese puñado de hombres que se reunieron sobre los escombros y viajando a través de ellos, después de 6 años de guerra espantosa, practicaron antes de separarse un acto solemne e imperecedero de tolerancia al rendir homenaje el mismo día y a la misma hora a dos grandes filósofos que habían muerto en campos ideológicamente opuestos: Pilo Albertelli, fusilado por los na. zis en la Fossa Ardeatina y Gioavnni Gentile, senador fascista, asesinado en su casa el mes de abril de 1944.

Fué además un acto de extraordinario valor porque como lo rematcó Enrique Castelli en su Discurso de Clausura, sustituyó el vencer por el convencer y rompió el ominoso silencio "que se ha alzado sobre nuestro mundo y que frustra la comprensión tanto como el vocerío del ambiente político y económico".

Si, como dijo Ugo Spirito, la crisis social y política contemporánea, es, sobre todo, una crisis metafísica, el Congreso de Filosofía de Roma y el insólito aporte de la Palabra del Sumo Pontífice, servirán para desenmarañar la espesura de los prejuicios e intereses y establecer una paz auténtica y estable entre los hombres.

En resumen: el año 1946 ha sido, en Italia, de intensa actividad cultural.

En ciertos aspectos secundarios, -el cinema y la música por ejemplo,- se puede hablar de un alegre y dinámico despertar.

El cine italiano produjo, durante el año pasado, un notable film so. bre la Resistencia: "Ronia, ciud ad abjertaé que ha conmovido a los públicos del país, de Francia y de EE. UU.

$Y$ en el "Scala" de Milan se ha estrenado una opera de Ildebrando Pizzetti, titulada "El Oro", que ha conmovido también a las multitudes y que, según la crítica, es el fresco e ingenuo lirismo de Verdi ataviado con la técnica wagneriana.

En Pintura, de Chirico, de Pisis, Mafai, Morandi y Renato Gutusso están produciendo a la vez con fervor y decoro.

Hay numerosos grupos o cenáculos literarios que mantienen viva la llama del Espíritu: en Venezia, en torno a la Revista "Le ttere ed Arti" y a la Casa Editorial de Neri Pozza o en la Biblioteca de Masimo Botempelli o de Paola Massimo, se reunen con ese fin Diego Valeri, Manlio Dazzi, Aldo Camerino, Lea Quaretti. En Bologna, Giorgio Morandi, Roberto Longhi, y Giusseppe Raimondi han formado un Cenacolo personalmen. te restringido pero espiritualmente abierto a todas las corrientes cultil. rales de la época. En Milán pueden distinguirse dos grupos: el que preside Francesco Flora y el que dirige Elio Vittorini, Director del po- 
riódico comunista "Politecnico", con evidente intolerancia sectaria. De Robertis, Bonzanti, Carlo Emilio Gadda y Parronchi ejercen, juntos, la difícil representación de las inmarcesibles tradiciones espirituales de Florencia. Y en Roma, Moravia, Corrado Alvaro, Ungaretti, Brancati, Momnelli, de Libero, sobre y al margen de las pasiones políticas, se reunen constantemente para que las prerrogativas de la Cultura no sufran un desme. dro inmerecido en su tierra natal.

Hay evidentes signos de un nuevo Renacimiento el principal de los cuales es la forma como el pueblo y sus dirigentes, intelectuales y políticos, están siguiendo el consejo del Papa Pío XII de "permanecer impávidos" sobre las ruinas tratando de encontrar, dentro y fuera, en el espiritu y en el contorno, el sentido de las tribulaciones humanas.

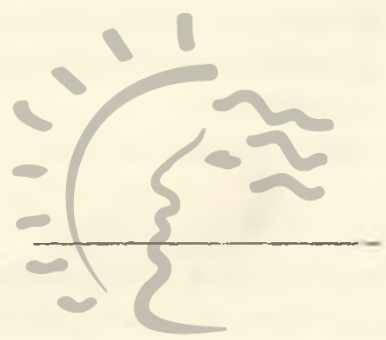

\section{Biblioteca de Letras} "Jorge Puccinelli Converso" 